\title{
Prevalence of Depression and Anxiety and Related Factors in Patients With Parkinson's Disease
}

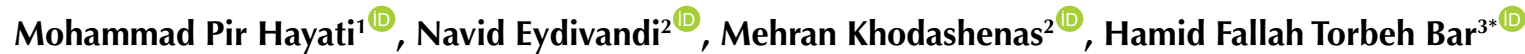 \\ ${ }^{1}$ School of Medicine, Iran University of Medical Sciences, Tehran, Iran \\ ${ }^{2}$ School of Medicine, Alborz University of Medical Science, Alborz, Iran \\ ${ }^{3}$ Resident of Internal Medicine, Iran University of Medical Sciences, Tehran, Iran
}

\begin{abstract}
Background: Parkinson's disease is a chronic and progressive disease in which patients show symptoms of psychiatric diseases such as anxiety and depression leading to decreased quality of life. So far, few studies have been done in this field in Iran.

Methods: The study is a cross-sectional study that investigates the prevalence of anxiety and depression and their related factors in patients with Parkinson's disease. In this study, 74 patients with Parkinson's disease and 74 healthy individuals were evaluated and using by Beck's Depression and Anxiety Inventories.

Results: The prevalence of depression and anxiety in patients with Parkinson's was $37.83 \%$ and $78.38 \%$, respectively. The mean score of depression and anxiety was significantly higher in the patient group $(P<0.001)$. Older age, female sex, a higher level of education and a longer duration of illness were significantly associated with more depression and anxiety $(P<0.05)$. Multiple regression models showed that age was a predictive factor in depression. With respect to anxiety, age and duration of the disease were predictive factors.

Conclusion: The severity of depression and anxiety were significantly higher in patients with Parkinson's disease compared to healthy individuals. Age and duration of the disease play a significant role in predicting the severity of depression and anxiety in such patients.

Keywords: Parkinson's disease; Depression; Anxiety; Prevalence; Beck Depression Inventory-II; Beck's Anxiety Inventory
\end{abstract}

\author{
*Correspondence to \\ Hamid Fallah Torbeh Bar, \\ Resident of Internal Medicine, \\ Iran University of Medical \\ Sciences, Tehran, Iran. \\ Email: dr.hamid.fallah@gmail. \\ com
}

Published online March 27 2021

Citation: Pir Hayati M, Eydivandi N, Khodashenas M, Fallah Torbeh Bar H. Prevalence of depression and anxiety and related factors in patients with parkinson's disease. Clin Neurosci J. 2021;8(2):85-89. doi:10.34172/icnj.2021.18.

\section{Introduction}

Parkinson's disease, the most common neurodegenerative disease after Alzheimer's, has a chronic and progressive nature. ${ }^{1}$ It usually appears after the age of 60 , and one in 100 people over the age of 60 develop Parkinson's disease. ${ }^{2}$ The prevalence of this disease in Iran is 2 in 1000 , and this ratio increases ten times in individuals over $60 .^{3}$ Parkinson's disease is usually characterized by the presence of two or more of the four main symptoms, namely resting tremor, bradykinesia, rigidity, and impaired balance and coordination. ${ }^{1}$

Although Parkinson's disease is a movement disorder, it can also have non-motor aspects such as dementia, depression, and functional and cognitive impairments. ${ }^{4,5}$ Among the non-motor complications, depression and anxiety are the most common psychiatric disorders in Parkinson's disease. ${ }^{5}$ The prevalence of depression ranges from $7.2 \%$ to $90 \%$, but studies on the prevalence of anxiety in Parkinson's disease are scarce and a few number of studies have reported a prevalence of $25 \%-52 \%{ }^{6,7}$ As Parkinson's disease progresses, the health-related quality of life (HRQOL) of patients and their caregivers gradually decrease. ${ }^{2}$ Some of the most important factors that reduce the quality of life of patients are psychiatric disorders such as depression and anxiety, which are also associated with increased mortality in these patients. ${ }^{5,8}$

Despite the importance of these issues, few studies have explored this area. In Iran, one study on patients with Parkinson's disease reported the prevalence of depression and cognitive disorders in these patients to be $45.6 \%$ and $32.9 \%$, respectively. ${ }^{9}$ Moreover, another study on patients with Parkinson's disease showed a prevalence of $44 \%$ for major depression. ${ }^{10}$ Lack of sufficient research on the prevalence of depression and anxiety in patients with Parkinson's disease, especially in Iran, encouraged us to conduct a study in this area. By better understanding the role of these factors in these patients, we can find a more effective way to control the disease and improve patients'

(C) 2021 The Author(s). This is an open access article distributed under the terms of the Creative Commons Attribution License (http:// creativecommons.org/licenses/by/4.0/), which permits unrestricted use, distribution, and reproduction in any medium, provided the original work is properly cited. 
quality of life.

\section{Materials and Methods}

This cross-sectional study was done in Hazrat Rasoul Akram hospital, Tehran, during the first six months of 2019 , to assess the prevalence of anxiety and depression and their related factors in patients with Parkinson's disease. Convenient sampling was used for patient selection. Beck's Depression Inventory-II (BDI-II) and Beck's Anxiety Inventory (BAI) were used to assess patients' depression and anxiety, respectively.

\section{Beck's Depression Inventory-II}

This questionnaire consists of 21 items, and the cumulative score can vary between zero and 63. A cumulative score between 0-18 represents no depression, 18-28 shows mild depression, 29-35 shows moderate depression, and 36-63 represents severe depression. ${ }^{11}$ The validity and reliability of the questionnaire have been previously confirmed. ${ }^{12-14}$ In Iran, Rajabi and Karju Kasmai confirmed the validity and reliability of the Persian versions of these inventories. ${ }^{11}$ Beck's Anxiety Inventory

This questionnaire consists of 21 items that each examines one of the symptoms of anxiety. The final score of this questionnaire ranges from zero to 63 that can represent one of the following: $0-7=$ minimal anxiety, $8-15=$ mild anxiety, $16-28=$ moderate anxiety, $29-63=$ severe anxiety. ${ }^{15}$ The validity and reliability of this questionnaire has been previously proven. ${ }^{14}$ The validity and reliability of the Persian version of this questionnaire was confirmed by Kaviani and Mousavi in 2008. ${ }^{16}$

\section{Sample Size Calculation and Statistical Analysis}

Based on Bahrami and colleagues' study, the sample size of the present study was calculated to be 74 for both case and control groups. ${ }^{9}$ Analysis was performed using SPSS software (IBM SPSS Statistics for Windows, version 22.0. Armonk, NY: IBM Corp). Quantitative data were reported as mean and standard deviation and qualitative data as percentages. Kolmogorov-Smirnov and Shapiro-Wilk tests were used to investigate normal data distribution. Multivariate analysis of variance (MANOVA) was used to evaluate the effect of anxiety and depression between the patient group and healthy individuals. Chi-square test, Pearson's correlation, and Cramer's V method were used to examine the correlation between age, sex, level of education, and duration of the disease with the results of Beck's depression and anxiety inventories. Multiple regression analysis was also used to determine the predictive value of age, sex, level of education, and the duration of disease on the dependent variables of anxiety and depression.

\section{Results}

In this study, 74 patients with Parkinson's disease were compared with 74 healthy individuals. There was no significant difference between the two groups in terms of sex and the level of education $(P>0.05$, Table 1$)$.

Table 1. Demographic data and the results of Beck's depression and anxiety inventories

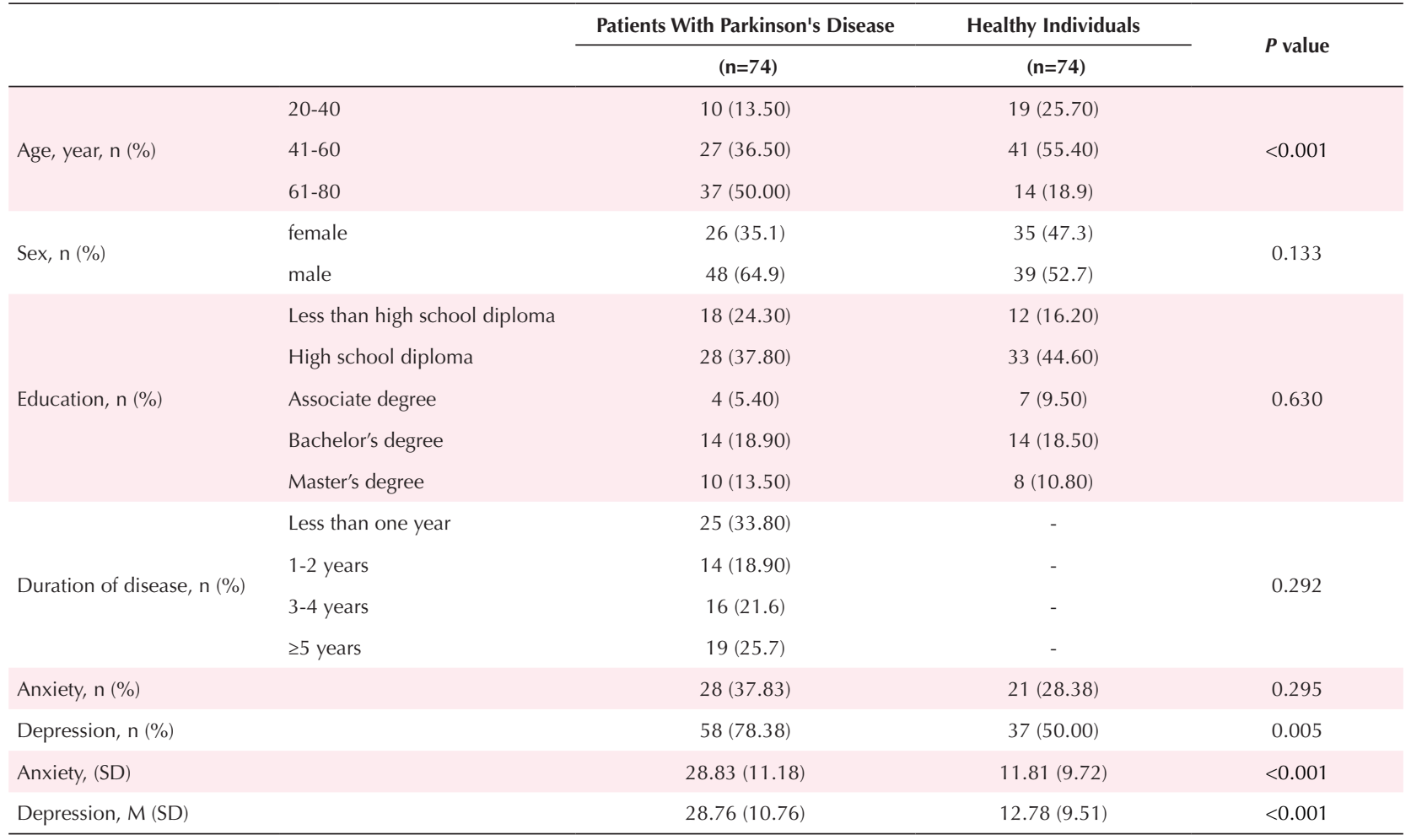


Significantly more individuals in the patient group were older than $60(P<0.001$, Table 1$)$. Most patients had a disease duration of less than 2 years. The prevalence of depression and anxiety in the patient group were $37.83 \%$ and $78.38 \%$, respectively. The prevalence of anxiety was higher among patients with Parkinson's disease compared to healthy individuals $(P=0.005)$, but the prevalence of depression was not significantly different between the two groups $(P=0.295)$. However, the mean score of depression and anxiety in the patient group was significantly higher than the healthy group $(P<0.001)$.

Table 2 shows the mean cumulative scores of Beck's depression and anxiety inventories as categorized by age, sex, level of education, and the duration of disease. The results showed that there was a significant correlation between an older age, female sex, a higher level of education and a longer duration of disease and higher levels of depression and anxiety $(P<0.05$, Table 3$)$. Given the correlation between independent variables of age, sex, level of education and duration of the disease with depression and anxiety, as well as a lack of multicollinearity, we performed a multiple regression analysis. The results showed that older age was a significant predictor of depression $(\beta=5.48, P=0.004)$. Our model also showed that older age $(\beta=4.64, P=0.006)$ and longer duration of illness $(\beta=3.30, P=0.001)$ were significant predictors of anxiety (Table 4$)$.

\section{Discussion}

Parkinson's disease is a disease of the central nervous system that is commonly seen in the elderly and causes symptoms such as resting tremor, bradykinesia, rigidity,

Table 2. Mean Scores of Depression and Anxiety by Demographics Variables

\begin{tabular}{|c|c|c|c|}
\hline & & $\begin{array}{c}\text { Depression } \\
(n=74)\end{array}$ & $\begin{array}{r}\text { Anxiety } \\
(n=74)\end{array}$ \\
\hline & & Mean (SD) & Mean (SD) \\
\hline \multirow{3}{*}{ Age, year } & $20-40$ & $23.20(10.43)$ & $21.40(13.57)$ \\
\hline & $41-60$ & $25.81(10.90)$ & $26.88(11.95)$ \\
\hline & $61-80$ & $32.62(9.56)$ & $32.27(8.60)$ \\
\hline \multirow{2}{*}{ Sex } & Female & $29.03(8.59)$ & $28.92(8.28)$ \\
\hline & Male & $28.77(11.85)$ & $28.79(12.55)$ \\
\hline \multirow{5}{*}{ Education } & $\begin{array}{l}\text { Less than high } \\
\text { school diploma }\end{array}$ & $27.66(9.02)$ & $29.33(10.23)$ \\
\hline & High school diploma & $28.71(11.13)$ & $27.00(11.07)$ \\
\hline & Associate degree & $27.75(17.28)$ & $27.75(10.99)$ \\
\hline & Bachelor's degree & $26.00(12.20)$ & $26.85(15.02)$ \\
\hline & Master's degree & $35.90(5.27)$ & $36.30(1.70)$ \\
\hline \multirow{4}{*}{$\begin{array}{l}\text { Duration of } \\
\text { disease }\end{array}$} & Less than one year & $23.96(11.59)$ & $26.00(10.79)$ \\
\hline & $1-2$ years & $27.57(8.30)$ & $27.50(12.79)$ \\
\hline & $3-4$ years & $30.12(10.74)$ & $29.75(11.09)$ \\
\hline & $\geq 5$ years & $35.21(8.21)$ & $32.78(10.05)$ \\
\hline
\end{tabular}

Table 3. Correlation Between Depression and Anxiety With Demographic Variables

\begin{tabular}{llcccc}
\hline \multirow{2}{*}{ Test type } & $\begin{array}{l}\text { Independent } \\
\text { Variable }\end{array}$ & \multicolumn{2}{c}{ Depression } & \multicolumn{3}{c}{ Anxiety } \\
\cline { 3 - 6 } & Age & 0.349 & 0.002 & 0.346 & 0.003 \\
\hline $\begin{array}{l}\text { Pearson } \\
\text { correlation }\end{array}$ & R Value & $\mathbf{R}$ & $\boldsymbol{P}$ Value \\
\hline Cramer's V & Sex & 0.750 & 0.046 & 0.745 & 0.041 \\
Chi-square & $\begin{array}{l}\text { Level of } \\
\text { education }\end{array}$ & 176.02 & $<0.001$ & 137.32 & 0.030 \\
$\begin{array}{l}\text { Pearson } \\
\text { correlation }\end{array}$ & $\begin{array}{l}\text { Duration of } \\
\text { disease }\end{array}$ & 0.406 & $<0.001$ & 0.240 & 0.039 \\
\hline
\end{tabular}

Table 4. Results of Multiple Regression Models

\begin{tabular}{llccc}
\hline \multicolumn{1}{l}{$\begin{array}{l}\text { Predictable } \\
\text { variables }\end{array}$} & $\boldsymbol{\beta}$ & $\mathbf{T}$ & $\boldsymbol{P}$ Value \\
\hline \multirow{5}{*}{ Anxiety } & Constant & 3.19 & 0.439 & 0.662 \\
& Sex & 3.43 & 1.28 & 0.202 \\
& Age & 5.48 & 3.02 & 0.004 \\
& Education & 1.56 & 1.77 & 0.080 \\
& Duration of disease & 1.65 & 1.53 & 0.129 \\
& Constant & 0.176 & 0.027 & 0.979 \\
& Sex & 4.36 & 1.81 & 0.074 \\
& Age & 4.64 & 2.82 & 0.006 \\
& Education & 1.50 & 1.88 & 0.063 \\
& Duration of disease & 3.30 & 3.39 & 0.001 \\
\hline
\end{tabular}

and postural instability. ${ }^{1}$ In addition to movement disorders, this disease is also associated with psychiatric disorders. ${ }^{4,5}$ The most common psychiatric disorders in patients with Parkinson's disease are depression and anxiety. ${ }^{5}$ Since no extensive studies in Iran have thoroughly explored this area, we aimed to investigate the prevalence of anxiety and depression and their related factors in Iranian patients with Parkinson's disease.

The results of this study showed that the prevalence of depression and anxiety in patients with Parkinson's disease were $37.83 \%$ and $78.38 \%$, respectively, and the comparison of depression and anxiety scores between the two groups showed higher scores in the patient group. In Bahrami and colleagues' study with 79 patients, the prevalence of depression and cognitive disorders were $45.6 \%$ and $32.9 \%$, respectively. ${ }^{9}$ In another study in Iran with 350 patients with Parkinson's disease, the prevalence of major depressive disorder was $44 \% .{ }^{10}$ Other studies also reported a prevalence of $16 \%-17.11 \%$ for depression and $19 \%-81.25 \%$ for anxiety in patients with PD. ${ }^{17,18}$

In the present study, we concluded that older age, female sex, a higher education level, and a longer duration of illness were significantly correlated with higher depression and anxiety levels. Multiple regression models also showed that older age was a significant predictor of depression and that an older age and a longer duration of illness were significant predictors of anxiety. Wee et al conducted a prospective longitudinal study of 89 patients with Parkinson's disease over 6 months, that showed the severity of depression was correlated with the severity of 
movement disorders, apathy and anxiety, and was also higher in female patients; while the severity of anxiety was correlated with older age, higher levels of education, a shorter illness duration, illness onset at a younger age, and higher daytime sleepiness. They also concluded that despite the coexistence of anxiety and depression, both have a separate and different longitudinal correlation with demographic variables and motor and non-motor factors. ${ }^{5}$ Other studies found a correlation between marital status, more severe movement disorders, dyskinesia, higher Hamilton anxiety rating scale, higher Parkinson's disease sleep scale, female sex, more severe cognitive impairment, insomnia, and daily drowsiness with depression. They also mentioned a correlation between anxiety and factors such as female sex, a higher C2 score, and a higher Hamilton score. ${ }^{17,18}$

According to the results of the present study and previous ones, the prevalence and severity of depression and anxiety in patients with Parkinson's disease is higher than healthy individuals and the severity and prevalence are related to factors such as old age, female sex, a higher education level and the duration of disease. As a result, physicians should pay more attention to this group of patients to improve their HRQOL through a timely diagnosis and simultaneous treatment of depression and anxiety.

\section{Limitations of the Study}

This study was performed in one hospital in Tehran for a limited period of time, so we should be cautious about generalizing the results of this study, and we also recommend more extensive, longitudinal studies with larger sample sizes be conducted in this area.

\section{Conclusion}

The severity of depression and anxiety in patients with Parkinson's disease was significantly higher than those of healthy individuals, and factors such as an older age, female sex, a higher level of education and a longer duration of disease were associated with higher levels of depression and anxiety.

\section{Conflict of Interest}

The authors declare that they have no conflict of interests.

\section{Authors' Contribution}

$\mathrm{MPH}$ performed the date gathering and analysis, NE drafted the primary manuscript, MK edited the manuscript for its intellectual contents, and HFTB supervised the project and provided critical feedback regarding the paper.

\section{Funding/Support \\ None.}

\section{Informed Consent}

Informed consent was obtained from all patients.

\section{Ethical Statement}

This study was approved by Iran University of Medical Sciences (IR. IUMS.FMD.REC.1398.320) and all participants provided informed consent prior to participation. This research involved human participants; however, none were exposed to any potential harm since we used questionnaires.

\section{References}

1. Baghoori D, Rezaei M, Mirzakhani N, Irani A, Akbarzadeh Baghban A. Face and content validity of Persian version of Parkinson Fatigue Scale (PFS-16) in people with Parkinson's disease. Scientific Journal of Rehabilitation Medicine. 2016;5(1):85-92.

2. Carod-Artal FJ, Ziomkowski S, Mourão Mesquita H, MartínezMartin P. Anxiety and depression: main determinants of healthrelated quality of life in Brazilian patients with Parkinson's disease. Parkinsonism Relat Disord. 2008;14(2):102-8. doi: 10.1016/j.parkreldis.2007.06.011.

3. Soleimani MA, Bastani F, Negarandeh R, Greysen R. Perceptions of people living with Parkinson's disease: a qualitative study in Iran. Br J Community Nurs. 2016;21(4):18895. doi: 10.12968/bjcn.2016.21.4.188.

4. Roohani M, Shahidi G, Miri S. Demographic study of Parkinson's disease in Iran: data on 1656 cases. Iran J Neurol. 2011;10(1-2):19-21.

5. Wee N, Kandiah N, Acharyya S, Chander RJ, Ng A, Au WL, et al. Depression and anxiety are co-morbid but dissociable in mild Parkinson's disease: a prospective Iongitudinal study of patterns and predictors. Parkinsonism Relat Disord. 2016;23:50-6. doi: 10.1016/j.parkreldis.2015.12.001.

6. Schrag A, Taddei RN. Depression and anxiety in Parkinson's disease. In: Chaudhuri KR, Titova N, eds. International Review of Neurobiology. Vol 133. Academic Press; 2017. p. 623-55.

7. Sarokhani D, Parvareh M, Hasanpour Dehkordi A, Sayehmiri K, Moghimbeigi A. Prevalence of depression among Iranian elderly: systematic review and meta-analysis. Iran J Psychiatry. 2018;13(1):55-64.

8. Pachana NA, Egan SJ, Laidlaw K, Dissanayaka N, Byrne GJ, Brockman S, et al. Clinical issues in the treatment of anxiety and depression in older adults with Parkinson's disease. Mov Disord. 2013;28(14):1930-4. doi: 10.1002/mds.25689.

9. Bahrami P, Zibaee M, Zebardast H, Ebrahimzadeh F, Yadegari S, Rezaee M. Evaluation of disabilities of Parkinson's disease patients in neurology ward of Shohaday-e-Ashayer hospital and private neurology clinics in 2010. Yafteh. 2012;14(3):2535. [Persian].

10. Shakeri J, Chaghazardi M, Abdoli N, Arman F, Hoseini SD, Shakeri $\mathrm{H}$. Disease-related variables and depression among Iranian patients with Parkinson's disease. Iran Red Crescent Med J. 2015;17(10):e30246. doi: 10.5812/ircmj.30246.

11. Rajabi G, Karju Kasmai S. Psychometric properties of a Persian language version of the Beck Depression Inventory second edition. Educational Measurement. 2013;3(10):139158. [Persian].

12. García-Batista ZE, Guerra-Peña K, Cano-Vindel A, HerreraMartínez SX, Medrano LA. Validity and reliability of the Beck Depression Inventory (BDI-II) in general and hospital population of Dominican Republic. PLoS One. 2018;13(6):e0199750. doi: 10.1371/journal.pone.0199750.

13. Visser M, Leentjens AF, Marinus J, Stiggelbout AM, van Hilten JJ. Reliability and validity of the Beck Depression Inventory in patients with Parkinson's disease. Mov Disord. 
2006;21(5):668-72. doi: 10.1002/mds.20792

14. Huang SL, Hsieh CL, Wu RM, Lu WS. Test-retest reliability and minimal detectable change of the Beck Depression Inventory and the Taiwan Geriatric Depression Scale in patients with Parkinson's disease. PLoS One. 2017;12(9):e0184823. doi: 10.1371/journal.pone.0184823.

15. Fydrich T, Dowdall D, Chambless DL. Reliability and validity of the Beck Anxiety Inventory. J Anxiety Disord. 1992;6(1):5561. doi: 10.1016/0887-6185(92)90026-4.

16. Kaviani $\mathrm{H}$, Mousavi AS. Psychometric properties of the Persian version of Beck Anxiety Inventory (BAI). Tehran Univ Med J. 2008;66(2):136-40. [Persian].

17. Zhu K, van Hilten JJ, Marinus J. Onset and evolution of anxiety in Parkinson's disease. Eur J Neurol. 2017;24(2):404-11. doi: 10.1111/ene.13217.

18. Cui SS, Du JJ, Fu R, Lin YQ, Huang P, He YC, et al. Prevalence and risk factors for depression and anxiety in Chinese patients with Parkinson's disease. BMC Geriatr. 2017;17(1):270. doi: 10.1186/s12877-017-0666-2. 